\title{
Basal melting of Ross Ice Shelf from solar heat absorption in an ice-front polynya
}

\author{
Craig L. Stewart, ${ }^{1,2 *}$ Poul Christoffersen, ${ }^{1}$ Keith W. Nicholls, ${ }^{3}$ \\ Michael J. M. Williams, ${ }^{2}$ Julian A. Dowdeswell ${ }^{1}$ \\ ${ }^{1}$ Scott Polar Research Institute, University of Cambridge, UK \\ ${ }^{2}$ National Institute of Water and Atmospheric Research, Wellington, NZ \\ ${ }^{3}$ British Antarctic Survey, Cambridge, UK
}

\begin{abstract}
March 14, 2019
Abstract

Ice-ocean interactions at the base of Antarctic ice shelves are rarely observed, yet have a profound influence on ice sheet evolution and stability. Ice sheet models are highly sensitive to assumed ice shelf basal melt rates; however, there are few direct observations of basal melting or the oceanographic processes that drive this, and consequently our understanding of these interactions remains limited. Here we use new in-situ observations from the Ross Ice Shelf to examine the oceanographic processes that drive basal ablation of the world's largest ice shelf. We show that basal melt rates beneath a thin and structurally important part of the shelf are an order of magnitude higher than the shelf-wide average. This melting is strongly influenced by a seasonal inflow of solar-heated surface water from the adjacent Ross Sea Polynya that downwells into the ice shelf cavity, nearly tripling basal melt rates during summer. Melting driven by this frequently overlooked process is expected to increase with predicted surface warming. We infer that solar heat absorbed in ice front polynyas can make an important contribution to the present-day mass balance of ice shelves, and potentially impact their future stability.
\end{abstract}




\section{Main}

The ice shelves that fringe Antarctica interact with the Southern Ocean across a basal surface of $1.56 \times 10^{6} \mathrm{~km}^{2}$ [1]. Melting of this vast surface is the single largest cause of mass loss from the Antarctic Ice Sheet $[1,2]$. Thinning induced by ice shelf basal melting can also modify inland ice flow, reducing the stabilising effect of sills, shoals and sidewalls $[3,4]$, in some cases driving instantaneous dynamic responses as far as $900 \mathrm{~km}$ inland [4]. Although these processes provide a primary control on the future evolution of the ice sheet $[3,5]$, there are still relatively few direct observations of basal melting and oceanographic conditions within ice shelf cavities [6], and this paucity of data impedes the development of theory and models.

In Antarctic shelf seas, three main water masses are thought to influence ice shelves [7]: Circumpolar Deep Water (CDW), a relatively warm water mass that surrounds Antarctica at intermediate depth; high and low salinity Shelf Water (HSSW and LSSW), which is formed as the sea surface freezes during winter; and Antarctic Surface Water (AASW), a relatively fresh and buoyant water mass influenced by solar heating and sea ice melting during summer [8].

These water masses have contrasting impacts on ice shelves. CDW in the Amundsen Sea has caused ice shelves in the region to thin over recent decades $[9,10]$ driving mass loss from the interior ice sheet $[11,12]$. In contrast, the vast Ross and Filchner-Ronne ice shelves appear to be near equilibrium $[13,14]$, due to the presence of cold Shelf Waters that limit their exposure to CDW $[8,15,16]$. The influence of AASW on ice shelves is less clear and seldom considered. Although buoyant, AASW can enter ice shelf cavities due to wind $[17,18]$ and tidal forcing [19-21]; however, observations of AASW beneath ice shelves have only been made recently $[22,23]$, and few studies have examined this process in detail.

For the Ross Ice Shelf (RIS), which at $500809 \mathrm{~km}^{2}$ [1], accounts for $32 \%$ of Antarctica's total ice shelf area, recent satellite observations suggest relatively low shelf-wide mean basal 
melt rates of 0.07 to $0.11 \mathrm{~m} \mathrm{yr}^{-1}[1,2,24]$. However, these studies also indicate rates above $1 \mathrm{~m} \mathrm{yr}^{-1}$ in the north-western sector of the shelf [1,24]. Although remote sensing estimates have uncertainties of over $100 \%$ [24], earlier glaciological observations [25-27] and oceanographic models [23,28-31] also indicate rapid melting in the north-western RIS. These models suggest that active circulation of frontal water into the cavity during summer and low-frequency flow variability may influence this region. Isolated observations from beneath the ice shelf support this picture $[23,31]$; however, the details of these processes and the magnitude of their impact on the ice shelf remain unclear.

Here we present new in-situ observations of basal melting and sub-ice shelf oceanographic conditions from the north-western RIS. The aims of the study are two-fold; to quantify and map basal ablation in the region surrounding Ross Island, and to examine the role of surface water in driving this process.

\section{Radar mapping of basal melting}

To quantify basal melting of the north-western RIS, we used a downward-looking phase-sensitive radio echo sounder $[32,33]$ to make precise measurements at 78 sites surrounding Ross Island (Fig. 1). All sites were resurveyed after one year, allowing annual-mean ablation rates to be calculated (see Methods and Supplementary Table 1). Further observations were used to determine short-term summer melt rates near the ice front (Supplementary Table 2). To map the melt rate field and estimate the total basal mass loss from the region, the melt rate observations were interpolated onto a regular grid (see Methods).

The observations show intense basal melting within $1 \mathrm{~km}$ of the ice shelf front, with annualmean rates of 2.4 to $7.7 \mathrm{~m} \mathrm{yr}^{-1}$ in this zone (Fig. 1). Melt rates reduce exponentially with distance from the ice front, typically halving within the frontal $3 \mathrm{~km}$ (Fig. 1b). This pattern is consistent with trends inferred from laser altimetry [34]; however, our observations show higher 
melt rates, and reveal small-scale spatial variability.

The melt rate observations indicate strong seasonal melt rate variability, with rapid summer melting especially pronounced near the ice front and on Transec TC (Fig. 1c). Here, a maximum ablation of $0.714 \pm 0.007 \mathrm{~m}$ was recorded over a 4.89 day period during January 2013, indicating a melt rate of $0.146 \mathrm{~m} \mathrm{~d}^{-1}\left(53 \mathrm{~m} \mathrm{yr}^{-1}\right)$ (Supplementary Table 2). This rate is a factor of 6.9 higher than the annual-mean rate at the same site, suggesting that a large component of the net ablation occurs in summer.

Beyond the frontal $15 \mathrm{~km}$, ablation rates are lower, yet still considerably above the shelf wide average of $\sim 0.1 \mathrm{~m} \mathrm{yr}^{-1}[1,2,24]$. The pattern of melting implies that net heat flux into the cavity is strongest $\sim 20 \mathrm{~km}$ east of Ross Island, near an embayment where frontal ice thickness is just $\sim 100 \mathrm{~m} \mathrm{[35].} \mathrm{In} \mathrm{this} \mathrm{area,} \mathrm{rapid} \mathrm{melting} \mathrm{extends} \mathrm{further} \mathrm{from} \mathrm{the} \mathrm{ice} \mathrm{front} \mathrm{(Fig.} \mathrm{1a).} \mathrm{The}$ mean basal melt rate across the $7782 \mathrm{~km}^{2}$ interpolated area is $1.34 \mathrm{~m} \mathrm{yr}^{-1}$, indicating a basal mass loss of $9.5 \mathrm{Gt} \mathrm{yr}^{-1}$. This represents $20 \%$ of the published net basal mass loss from the entire RIS [1] from $1.6 \%$ of its area.

The rapid frontal melting and the large seasonal variations in melt rates suggest that melting near the ice front may be influenced by an inflow of warm surface water during summer, as observed beneath McMurdo Ice Shelf [23]. As warm inflowing water is expected to progressively cool through contact with the ice base, this mechanism could also explain the exponential reduction in melt rate with frontal distance.

\section{Oceanographic observations}

To examine the oceanographic processes that drive enhanced melting in the north-western sector of RIS, a sub-ice shelf mooring was deployed $7 \mathrm{~km}$ from the ice front on Transect TB (Fig. 1a). Moored instruments recorded currents, temperature and salinity hourly for up to 4 years. In addition, an Upward Looking Sonar (ULS) deployed beneath the ice base allowed basal melt 
rates to be determined (see Methods).

Currents at the mooring site show strong seasonal variability, with mean depth-averaged outflows during winter (April-November) and inflows during late summer (February-March) (Fig 2a). The strength and duration of this inflow imply ventilation of the outer $\sim 50$ to $160 \mathrm{~km}$ of the cavity. Comparison of water temperature at the mooring with sea surface temperature (SST) [36] north of the ice front suggests the inflow has a direct impact on temperatures within the cavity (Fig. 2c). Averaged over the region within $100 \mathrm{~km}$ of the mooring, SST follows an annual cycle closely linked to mean sea ice concentration in the same region (Fig. 2c). Here temperatures vary from the surface freezing point during winter, to seasonal maxima of over $1{ }^{\circ} \mathrm{C}$ in January when sea ice is absent. Temperatures measured $\sim 13 \mathrm{~m}$ below the ice base at the mooring show a similar but delayed and attenuated cycle; with seasonal maxima occuring in February, $\sim 1$ month after the SST peak.

Further clues to the origin of the warm inflow are provided by a single serendipitous Conductivity Temperature Depth (CTD) cast, sampled $120 \mathrm{~km}$ north of the mooring site (Fig. 2a) one day prior to the mooring deployment [37]. This cast shows a $40 \mathrm{~m}$ thick, relatively fresh upper layer with a surface temperature of $0.178^{\circ} \mathrm{C}$ (Fig. 2b). The $0.8^{\circ} \mathrm{C}$ temperature range of the upper $35 \mathrm{~m}$ is associated with a salinity range of just $0.009 \mathrm{psu}$, suggesting solar heating of a previously homogenous layer. Comparison of the CTD cast with Temperature-Salinity (TS) observations from the upper moored sensor, located $8 \mathrm{~m}$ below the ice base $(\sim 229 \mathrm{~m}$ below sea level), suggests that surface water is drawn into the cavity. By extending the extrema of the offshore CTD cast with $2.4^{\circ} \mathrm{Cpsu}^{-1}$ melt-water mixing lines $[16,38]$, we define an envelope of water masses that could be formed from the offshore water by interaction with the ice shelf. Throughout January and February 2011, all 863 observations from the upper sub-ice shelf TS sensor fall within this envelope (Fig. 2b). The sub-ice shelf observations are consistent with a source region in the offshore profile above $55 \mathrm{~m}$, indicating that the surface layer downwells 
to reach the mooring site. The characteristics of the warmest sub-ice shelf water are consistent with the mean properties of the upper $\sim 50 \mathrm{~m}$ of the offshore profile, suggesting that the surface layer is homogenized before reaching the mooring.

The impact of water temperature variability on the ice shelf is illustrated by comparing the ULS basal melt rate record with water temperature from the upper moored current meter (Fig. $2 \mathrm{~d}$ ). Both records are low-pass filtered (cutoff frequency $f_{c}=0.02$ cycle day $^{-1}$ ) to reduce the impact of noise in the range observations (see Methods). The dominant feature of the melt rate record is a strong seasonal cycle that peaks in February. The smoothed temperature and melt rate records are highly correlated (Pearson's $r=0.78$ ), indicating that water temperature is the dominant driver of low-frequency melt rate variability at the mooring site.

Considering the central 3-year period June 2011 - May 2014, the mean ULS melt rate is $1.8 \mathrm{~m} \mathrm{yr}^{-1}$ (Fig. 1b). Seasonally, melt rates vary between $1.1 \mathrm{~m} \mathrm{yr}^{-1}$ during late winter (September - November) when sub-ice shelf water temperatures are at or below the surface freezing point, and $3.0 \mathrm{~m} \mathrm{yr}^{-1}$ during summer (January - March) when surface water is seen at the site. This rapid melting occurs over a relatively short period, and the difference between the late-winter and annual-mean rates implies that summer melting accounts for $\sim 0.7 \mathrm{~m} \mathrm{yr}^{-1}$, or $\sim 40 \%$ of net ablation at the mooring site. Determining the contribution of surface water to net ablation over the wider survey region is more difficult due to the lack of winter melt rate observations away from the mooring site. However, the higher summer/annual-mean melt rate ratios seen on Transect TC, $20 \mathrm{~km}$ west of the mooring (Fig 1b,c and Supplementary Table 2) suggest that the influence of surface water is stronger here.

Although melt rates peak during February, winter rates are still an order of magnitude higher than the satellite-inferred shelf-wide average, and contribute significantly to the high average melt rates. This indicates that winter current speeds or water temperature at the mooring are higher than the shelf-wide average. Whilst localised flow enhancement may contribute 
to rapid melting in the region, it appears unlikely the flow variability could explain the order-ofmagnitude melt rate enhancement, and we suggest that temperature variability plays the dominant role. While there are few observations from elsewhere in the cavity, CTD profiles from the central RIS show a thick Ice Shelf Water boundary layer within $0.03^{\circ} \mathrm{C}$ of the in-situ freezing point [39]. In contrast, at the mooring site water near the ice base is often above the surface freezing point during early winter indicating remnant heat from the summer inflow. Even during late winter, $\mathrm{HSSW}$ some $0.17^{\circ} \mathrm{C}$ above the in-situ freezing point is frequently observed, and this suggests active cross-frontal flow that ventilates the cavity [40,41].

\section{Surface ocean heat}

The identification of a warm surface water inflow that drives rapid basal melting raises crucial questions; what is origin of this heat, and could this process influence other ice shelves? To address these questions, we examine summer SST and sea ice concentration observations from coastal Antarctica.

Figure 3a shows long-term mean January SST [36] and sea ice distribution, represented here by the mean $15 \%$ sea ice concentration contour [42] (see Methods). At the largest scale, summer SST is inversely correlated with sea ice concentration and the coldest waters are typically found near the coastline (Fig. 3a); however, higher temperatures are observed wherever significant open water exists, including coastal polynyas near the Ross and Amery ice shelves (see also [43]).

Within the Ross Sea, SST variability is dominated by a warm surface anomaly, previously identified in CTD observations [44], that closely matches the position of the Ross Sea Polynya (Fig. 3b). In this region, January-mean SST reaches $\sim 0.5{ }^{\circ} \mathrm{C}$. This pattern of warming is consistent with atmospheric modelling that indicates Antarctic polynyas absorb solar heat rapidly during summer [45], and has previously been attributed to summer insolation in the Ross Sea 
Polynya $[23,46]$.

To assess whether the warm surface pool evident in Fig. 3b could supply the energy required for elevated melting in the survey region, we calculated the available thermal energy within its surface waters during January (see Methods). Considering the region within the $0{ }^{\circ} \mathrm{C}$ SST isotherm (Fig. 3b), and assuming a surface mixed layer depth of $10 \mathrm{~m}$ implies a sensible heat content of $8.3 \times 10^{18} \mathrm{~J}$, sufficient to melt $22 \mathrm{Gt}$ of ice shelf. This is approximately twice the observed ablation within the survey region. Despite significant uncertainty in the mixed layer depth, surface waters in the Ross Sea clearly represent a glaciologically significant heat reservoir during summer.

Beyond the Ross Sea, coastal SSTs above $-0.5^{\circ} \mathrm{C}$ are only seen in the north-western Antarctic Peninsula where sea ice concentration is low, and in the polynya adjacent to the eastern Amery Ice Shelf (Fig. 3a). Consequently, while surface layer heat may affect these regions, this process does not appear to be widespread at present.

\section{Drivers and impacts of surface water inflow}

Although surface waters have been considered a potential driver of ice shelf basal melting for some time [7,22,23], the observations presented here provide the most detailed evidence of this process to date. These suggest that solar heated surface water contributes significantly to the basal mass balance of RIS, and that surface water plays a larger role in the mass balance of ice shelves than previously assumed.

In the north-western Ross Sea, the impact of surface water can be attributed to two processes; localised solar heating of the surface ocean during summer, and transport of this energy into the cavity by a seasonal inflow. Surface heating appears closely linked to the consistent wind-driven expansion of the Ross Sea Polynya during spring [23,46]. During this period, sustained southerly winds, guided by the Transantarctic Mountains, preferentially export sea 
ice from the western ice front $[47,48]$. As air temperatures and insolation increase throughout November and December, the polynya expands rapidly (Fig. 2c and Fig. 3b), as illustrated by the sea ice distribution during this period (Fig. 3c). This process increases solar energy absorption in the surface layer, and removes the latent-heat sink presented by sea ice, aiding rapid heating of the surface layer (Fig. 2c).

The drivers of the late-summer inflow are less obvious; however, due to the buoyancy of the surface layer, it appears likely that external forcing is required. In contrast to the wind-driven downwelling observed elsewhere [18], the inflow observed here is not associated with downwelling favourable winds. Modelling suggests shelf and sub-ice shelf circulation in the region is strongly influenced by density gradients caused by seasonal brine release in the polynya [41] and that these influence seasonal flow variability near Ross Island [28]. Considering these factors, we conclude that the elevated melt rates in the north-western RIS are linked to the location of Ross Sea Polynya, and ultimately the mean winds and orography of the region.

The identification of surface layer heat as a driver of basal melting on the RIS has several important implications. Firstly, as heat absorption within the polynya is controlled by atmospheric processes [45], basal mass balance within the frontal zone of the ice shelf is likely to vary with atmospheric and surface ocean conditions near the ice front on seasonal, inter-annual, and longer time scales. Considering that summer sea ice concentrations in the Ross Sea are projected to decrease by $56 \%$ by 2050 [49], and the ice free period is also expected to increase [50], it appears likely that ice shelf basal melting within this region will also increase rapidly. If surface warming and sea ice loss is widespread, this process may also become more widespread. Secondly, AASW drives a mode of basal ablation that is distinct from that of denser water masses, and these differences have implications for ice shelf stability. For example, whereas meltwater derived from HSSW can re-freeze in shallower regions potentially stabilising ice shelves [51]; due to its relative warmth, meltwater formed from AASW is unlikely 
to be redeposited. Furthermore, the influence of surface water is greatest in frontal regions. Although some frontal regions are unimportant to the stability of ice shelves, others contain critical pinning points that sustain the frontal location $[52,53]$. Ross Island appears to be one such pinning point, and recent modelling shows that the rapid melting identified here influences a structurally critical region where ice thickness changes can influence the flow speed of the entire ice shelf [4].

The exposure of this sensitive part of the ice shelf to surface ocean heat implies that grounding line flux of the entire ice shelf may be modulated at seasonal to inter-annual scales by the surface water inflow. This process represents a frequently overlooked but potentially important factor in regional ice shelf mass balance and should be considered in future assessments of ice shelf stability. 


\section{Methods}

\section{Radar observations}

Basal melt rates were measured using the British Antarctic Survey's Autonomous Phase-sensitive Radio Echo Sounder (ApRES) [33]. This Frequency Modulated Continuous Wave (FMCW) radar has a center frequency of $300 \mathrm{MHz}$ and bandwidth of $200 \mathrm{MHz}$. The instrument uses Direct Digital Synthesis to generate the linear 1s chirp, and demodulates the radio frequency carrier wave by mixing the receive $(\mathrm{Rx})$ signal with an attenuated feed of the transmit $(\mathrm{Tx})$ signal. The resulting audio frequency signal is digitized at $40 \mathrm{kHz}$. The same high-stability master clock is used to drive both signal generation and sampling, ensuring precise synchronization. Technical details of the instrument are given in [32].

The instrument was used in a pseudo-monostatic configuration, with Tx-Rx antenna separation of $3.44 \mathrm{~m}$. At each site an ensemble (burst) of typically 100 chirps were recorded. Radar sites were marked with surface stakes to ensure the same column of ice was sampled on each visit. Care was taken to ensure precise relocation of the instrument relative to the marks, and repositioning error was estimated as $<0.05 \mathrm{~m}$.

Data from each visit to each site were pre-processed as follows. For each burst, noisy chirps were removed, and the remaining chirps averaged. Each burst-mean chirp was weighted with a Blackman window, then extended to a multiple of 8 times its original length by appending trailing zeros. Following this zero-padding, the signal was circularly rotated so that the first sample of the modified signal was that of the centre of the unpadded chirp (see ref. [54]). Each chirp was then Fast Fourier Transformed.

Due to the frequency-range proportionality in linear FMCW radar observations [32], the amplitude of the resulting spectrum is analagous to a time-series of echo amplitude recorded by a time-domain radar. These complex valued spectra are hereafter referred to profiles. Without 
zero-padding the profiles have a frequency resolution of $1 \mathrm{~Hz}$, and the $200 \mathrm{MHz}$ bandwidth imples a temporal resolution of $5 \mathrm{~ns}$, corresponding to a range resolution of $0.43 \mathrm{~m}$ in ice. With zero-padding the interpolated range resolution is $0.0537 \mathrm{~m}$. Here and in the following analysis we assume a nominal propagation velocity of $1.68 \times 10^{8} \mathrm{~m} \mathrm{~s}^{-1}$ [55].

Although changes in the range of the basal reflector are relatively simple to determine, these are influenced by many factors including changes in radar hardware (e.g. cable length), compaction of the upper snow layers (firn), and strain within the solid ice and basal melting. To isolate the component due to basal ablation, observations of internal reflector displacement were used to tune a displacement model. This model was used to estimate the displacement of the ice base expected in the absence of basal melting. Net basal ablation is then determined from the difference between the expected and observed basal displacement. The approach used here is described in more detail in [54].

Vertical displacements between profiles observed at the same site were quantified by crosscorrelating overlapping $15 \mathrm{~m}$ segments of the profiles. This provided vertical displacement estimates at $7.5 \mathrm{~m}$ resolution throughout the ice shelf. First, the integer range-bin (or coarse) offset between the two profiles was determined by cross-correlation of the profile amplitude. Finescale offsets were determined from the mean phase difference between the profile segments. This was evaluated from the angle of the cross-correlation of the complex profile segments, after applying the coarse offset. The estimates of coarse and fine displacement were added to provide an estimate of total vertical displacement between the two profiles (Fig. S1).

The displacement of the ice base was estimated in a similar manner. Amplitude cross correlation was used to determine the coarse offset, and complex cross-correlation to determine the phase difference. Assuming the ice base to be the strongest peak in each profile, the coarse offset was determined using the $10 \mathrm{~m}$ segment of the first profile above the peak of the basal reflector. Phase difference was determined from the leading edge of the basal peak, defined here 
as the $1 \mathrm{~m}$ segment of the profile above the peak of the basal reflector.

The resulting estimates of vertical displacement throughout the profile were used to tune a model of displacement that was used to estimate the expected location of the base. The displacement model was formed to allow for the major processes expected to influence the observations, namely; hardware changes, accumulation, vertical strain and firn compaction. The model was of the form:

$$
\delta z(z)=A+B z+C e^{\left(-z / z_{0}\right)} .
$$

Here $\delta z(z)$ is the modelled vertical displacement of internal reflectors as a function of $z$, the range from the antenna calculated using a nominal propagation velocity of $1.68 \times 10^{8} \mathrm{~m} \mathrm{~s}^{-1}$. A represents a range independent offset allowing for hardware changes and surface accumulation. $B$ represents linear vertical strain, associated with horizontal convergence/divergence in the ice shelf. The third term on the right hand side represents an exponential model of firn compaction with surface compaction $C$, and length scale $z_{0}$. As many sites had insufficient depth to determine $z_{0}$ robustly, this was set to $21 \mathrm{~m}$ based on sites where this could be determined from the observations.

This model was used at all sites except the frontal site on Transect TB (tb_00000). Here, curvature in the deep displacement observations suggested bending, possibly caused by e.g. a submarine keel at the ice front [56]. To allow for this deformation, a more complex displacement model which also allows for vertical displacement caused by bending of the ice shelf was used at this site as follows:

$$
\delta z(z)=A+B z+C e^{\left(-z / z_{0}\right)}+D\left(z-z_{n}\right)^{2} .
$$

The final term here represents the vertical displacement induced by bending as a quadratic function of distance from neutral depth $z_{n}$ following ref. [57]. 
At each site the model free parameters were tuned to minimise the model-observation differences in a least squares sense, using non-linear optimisation. Following tuning the model was used to determine the displacement of the base expected in the absence of basal ablation. The melt rate was then determined from the difference between the observed and expected vertical displacement of the basal reflector and the observation interval (Supplementary Fig. 1).

Formal errors in the melt rate estimates are typically 0.01 to $0.1 \mathrm{~m} \mathrm{yr}^{-1}$ (Tables S1 and S2), usually dominated by the $1 \%$ uncertainty in the signal propagation speed in ice [55]. Systemic errors, such as the appropriateness of the firn compaction model are unaccounted for in the formal error estimate; however, the results are, within the stated errors, robust to reasonable variations in processing methods.

\section{Melt rate spatial interpolation}

In order to estimate net basal ablation from the survey region and to aid visualization of the melt rate field, the point-melt rate observations were interpolated onto a regular $1 \mathrm{~km}$ grid using the geostatistical interpolation method of Kriging [58]. Kriging is typically used where the underlying value of the assumed stochastic process being sampled is either constant (simple Kriging) or a linear function of position (Kriging with a trend). However, in this case melt rate variability is a strong non-linear function of frontal distance. To improve the statistical properties of the Kriged variable, the observed melt rates $\left(m_{o}\right)$ were first decomposed into a modelled component including a mean melt rate and a component of frontal melt enhancement $\left(m_{m}\right)$, and a melt rate anomaly $\left(m_{a}\right)$ (Supplementary Fig. 2), i.e.:

$$
m_{o}(x, y, d)=m_{m}(d)+m_{a}(x, y)
$$

Kriging was performed on the melt rate anomaly, and following interpolation, the frontal component determined for the grid location was added to the interpolated anomaly. This ap- 
proach is closely related to regression-Kriging [59]; however, in this case the explanatory variation is a non-linear function of the auxiliary variable (frontal distance).

Following ref. [34], frontal melt enhancement was modelled as an exponential function of frontal range. To accommodate the non-zero melt rates apparent at sites furthest from the ice front, a spatially constant term was added, providing a melt rate model of the form:

$$
m_{m}=\alpha+\beta e^{\left(-d / d_{f}\right)} .
$$

Here $\alpha$ is a spatially constant background melt rate, $\beta$ the magnitude of melt rate enhancement at the ice front, $d$ the distance to the front of the Ross Ice Shelf, and $d_{f}$ an e-folding length scale. While some frontal effect is evident on the McMurdo Ice Shelf, there are insufficient observations near the McMurdo Ice Shelf front to reliably tune a model of frontal melt enhancement. Furthermore, differences in SST between the RIS ice front and McMurdo Sound (Fig. 3b) suggest that differences between frontal effects in the two regions are likely. For these reasons, we do not model frontal melt enhancement for the McMurdo Ice Shelf.

Least squares fitting of the model to the 78 melt rate observations provided parameter estimates of $\alpha=1.29 \pm 0.09 \mathrm{~m} \mathrm{yr}^{-1}, \beta=5.0 \pm 0.4 \mathrm{~m} \mathrm{yr}^{-1}$ and $d_{f}=1900 \pm 300 \mathrm{~m}$. The model provides a good fit to the observations (Supplementary Fig. 2a) with a coefficient of determination $R^{2}=0.78$, confirming that much of the melt rate variability within the network can be described by this simple model of frontal melt enhancement.

Kriging with a linear trend was implemented using the mGstat toolbox [60] using a spherical semi-variogram with a sill of $0.45 \mathrm{~m}^{2} \mathrm{yr}^{-2}$ and a range of $40 \mathrm{~km}$; properties based on the observed spatial covariance of the melt rate anomaly (Supplementary Fig. 2b). After Kriging, the modelled melt rates (Supplementary Fig. 2c) were added to the interpolated anomaly field (Supplementary Fig. 2d) to produce the final gridded melt rate estimate (Fig. 1a). Kriging also provides an estimate of the variance of the interpolated value, and the resulting melt rate 
field was cropped to exclude land, sea, and regions where the standard deviation estimate was $>0.5 \mathrm{~m} \mathrm{yr}^{-1}$.

\section{Mooring}

The sub-ice shelf mooring was deployed on 21 January 2011 through a hot-water bored access hole at $77^{\circ} 29.315^{\prime} \mathrm{S}, 171^{\circ} 34.272^{\prime} \mathrm{E}$, approximately $7 \mathrm{~km}$ south of the ice front. Ice shelf and water column thickness at the deployment site were $266.5 \mathrm{~m}$ and $578 \mathrm{~m}$, respectively, and the sea bed depth was $798.5 \mathrm{~m}$. This deployment followed the 2-month deployment discussed in [31].

Nortek Aquadop current meters and Seabird SBE-37 temperature salinity instruments were located at 4 levels throughout the water column from $\sim 10 \mathrm{~m}$ below the ice base to $\sim 30 \mathrm{~m}$ above the sea bed. Further details of the moored instrumentation and processing are provided in [54].

The ULS was composed of an upward looking Tritech PA-500 acoustic altimeter, configured as an external sensor to a Nortek Aquadop current meter, mounted to the mooring wire $15 \mathrm{~m}$ below the ice base. To avoid detecting the deployment borehole, the sensor was tilted $13^{\circ}$ from the mooring wire, and its $5^{\circ}$ acoustic beam width implies a $\sim 2 \mathrm{~m}$ diameter acoustic footprint at the ice base. The instrument sampled every second hour from January 2011, until battery failure in December 2014.

The raw range record required significant processing to remove outliers and noise. Processing included removing outliers, correcting for mooring swing, sensor tilt, and sound speed variations. Remaining scatter in the range observations of $\pm 0.15 \mathrm{~m}$, attributed to basal roughness within the insonified region, was minimised by low-pass filtering the time series with a cut-off frequency of 0.02 cycle day $^{-1}$. Radar observations at the mooring site provide a precise and independent measure of basal melting that can be used to validate the ULS estimate. Between observations on 16 January 2013 and 10 January 2014, the radar and ULS indicate mean melt rates of $1.57 \pm 0.02 \mathrm{~m} \mathrm{yr}^{-1}$ and $1.66 \mathrm{~m} \mathrm{yr}^{-1}$. The $0.09 \mathrm{~m} \mathrm{yr}^{-1}$ discrepancy between the 
estimates is attributed to error in the ULS melt rate estimate. Further details of the instrument, processing and validation are given in [54].

\section{SST and sea ice concentration}

SST data were downloaded from the Group for High Resolution Sea Surface Temperature (GHRSST), Multiscale Ultrahigh Resolution L4 archive [36]. The time series in Fig. 2 was formed from daily foundation SST fields at a resolution of $5 \mathrm{~km}$, averaged over the region within $100 \mathrm{~km}$ of the mooring. The spatial fields in Fig. 3 were derived from daily foundation SST fields at $25 \mathrm{~km}$ resolution, averaged over all January samples within the years 2003-2018. Sea ice concentrations at $25 \mathrm{~km}$ resolution are from the NOAA/NSIDC Climate Data Record of Passive Microwave Sea Ice Concentration, Version 3, downloaded from the National Snow and Ice Data Centre, ftp://sidads.colorado.edu/pub/DATASETS/NOAA/G02202_V3/ south/monthly/ $[42,61]$. Monthly mean sea ice concentraions were averaged over the years 2010-2017.

\section{Polynya surface heat content}

To determine the available sensible heat content of the surface ocean layer within the polynya region during January, we estimated its mean properties as follows. Considering the $8.3 \times 10^{4} \mathrm{~km}^{2}$ region within the $0{ }^{\circ} \mathrm{C} \mathrm{SST}$ isotherm (Fig. 3b), the mean January SST is $0.22^{\circ} \mathrm{C}$. Based on the CTD cast in Figure $2 \mathrm{~b}$ we assume a surface salinity of $34.4 \mathrm{psu}$. The freezing point potential temperature of this water at a depth of $200 \mathrm{~m}$, typical of ice draft in the survey region (Fig 1a), is $-2.04^{\circ} \mathrm{C}$. This indicates a temperature difference between the surface layer and the ice base, or thermal driving [62], of $2.26^{\circ} \mathrm{C}$. Using a seawater density of $1030 \mathrm{~kg} \mathrm{~m}^{-3}$, this implies a thermal reservoir of $8.3 \times 10^{17} \mathrm{~J} \mathrm{~m}^{-1}$ of mixed layer depth. CTD observations [63] indicate a wide range of mixed layer depths within this region during summer, typically exceeding 
$10 \mathrm{~m}$. Assuming a mixed layer thickness of $10 \mathrm{~m}$ implies a surface layer sensible heat content of $8.3 \times 10^{18} \mathrm{~J}$. Using an ice density of $916 \mathrm{~kg} \mathrm{~m}^{-3}$, and an initial temperature of $-25^{\circ} \mathrm{C}$, indicative of surface temperatures in the region [25], this is sufficient to melt $22 \mathrm{Gt}$ of the ice shelf. 


\section{References}

[1] Rignot, E., Jacobs, S., Mouginot, J. \& Scheuchl, B. Ice-shelf melting around Antarctica. Science 341, 266-70 (2013). URL http: / /www.ncbi.nlm.nih.gov/pubmed/ 23765278.

[2] Depoorter, M. et al. Calving fluxes and basal melt rates of Antarctic ice shelves. Nature 502, 89-92 (2013).

[3] Arthern, R. J. \& Williams, C. R. The sensitivity of West Antarctica to the submarine melting feedback. Geophysical Research Letters 44, 2352-2359 (2017). URL https://agupubs.onlinelibrary.wiley.com/doi/abs/ 10.1002/2017GL072514. https://agupubs.onlinelibrary.wiley. com/doi/pdf/10.1002/2017GL072514.

[4] Reese, R., Gudmundsson, G. H., Levermann, A. \& Winkelmann, R. The far reach of ice-shelf thinning in Antarctica. Nature Climate Change 8, 53-57 (2018). URL https : //doi.org/10.1038/s41558-017-0020-x.

[5] Pattyn, F. Sea-level response to melting of Antarctic ice shelves on multi-centennial timescales with the fast Elementary Thermomechanical Ice Sheet model (f.ETISh v1.0). The Cryosphere 11, 1851-1878 (2017). URL https://www.the-cryosphere. net/11/1851/2017/.

[6] Jenkins, A., Nicholls, K. W. \& Corr, H. F. J. Observation and parameterization of ablation at the base of ronne ice shelf, antarctica. Journal of Physical Oceanography 40, 22982312 (2010). URL https: / / doi .org/10.1175/2010 JP04317.1. https : / / doi.org/10.1175/2010JP04317.1. 
[7] Jacobs, S., Hellmer, H., Doake, C., Jenkins, A. \& Frolich, R. Melting of ice shelves and the mass balance of Antarctica. Journal of Glaciology 38, 375-387 (1992).

[8] Orsi, A. H. \& Wiederwohl, C. L. A recount of Ross Sea waters. Deep Sea Research Part II: Topical Studies in Oceanography 56, 778-795 (2009). URL http: / / I inkinghub. elsevier.com/retrieve/pii/s0967064508003597.

[9] Jenkins, A. et al. Observations beneath Pine Island Glacier in West Antarctica and implications for its retreat. Nature Geoscience 3, 468-472 (2010).

[10] Paolo, F. S., Fricker, H. A. \& Padman, L. Volume loss from Antarctic ice shelves is accelerating. Science 348, 327-331 (2015).

[11] Velicogna, I., Sutterley, T. \& Van Den Broeke, M. Regional acceleration in ice mass loss from greenland and antarctica using grace time-variable gravity data. Geophysical Research Letters 41, 8130-8137 (2014).

[12] Shepherd, A. et al. Mass balance of the antarctic ice sheet from 1992 to 2017. Nature 556, 219-222 (2018).

[13] Shepherd, A. et al. Recent loss of floating ice and the consequent sea level contribution. Geophysical Research Letters 37, 1-5 (2010). URL http : / /www . agu . org/pubs / crossref/2010/2010GL042496. shtml.

[14] Pritchard, H. et al. Antarctic ice-sheet loss driven by basal melting of ice shelves. Nature 484, 502-505 (2012).

[15] Jacobs, S. S., Amos, A. F. \& Bruchhausen, P. M. Ross Sea oceanography and Antarctic Bottom Water formation. In Deep Sea Research and Oceanographic Abstracts, vol. 17, 935-962 (Elsevier, 1970). 
[16] Nicholls, K. W., Østerhus, S., Makinson, K., Gammelsrød, T. \& Fahrbach, E. Ice-ocean processes over the continental shelf of the southern Weddell Sea, Antarctica: A review. Reviews in Geophysics 47 (2009).

[17] Sverdrup, H. U. The currents off the coast of queen maud land. Norsk Geografisk Tidsskrift-Norwegian Journal of Geography 14, 239-249 (1954).

[18] Zhou, Q. et al. Wind-driven spreading of fresh surface water beneath ice shelves in the Eastern Weddell Sea. Journal of Geophysical Research: Oceans 119, 3818-3833 (2014).

[19] Gammelsrod, T. \& Slotsvik, N. Hydrographic and current measurements in the southern Weddell Sea 1979/80. Polarforschung 51, 101-111 (1981).

[20] Jenkins, A. \& Doake, C. S. M. Ice-ocean interaction on Ronne Ice Shelf, Antarctica. Journal of Geophysical Research 96, 791-813 (1991). URL http : / /www . agu . org / pubs/crossref/1991/90JC01952. shtml.

[21] Makinson, K. \& Nicholls, K. W. Modeling tidal currents beneath filchner-ronne ice shelf and on the adjacent continental shelf: Their effect on mixing and transport. Journal of Geophysical Research: Oceans 104, 13449-13465 (1999).

[22] Hattermann, T., Nø st, O. A., Lilly, J. M. \& Smedsrud, L. H. Two years of oceanic observations below the Fimbul Ice Shelf, Antarctica. Geophysical Research Letters 39, 1-6 (2012). URL http://www.agu.org/pubs/crossref/2012/ 2012GL051012.shtml.

[23] Stern, A. A., Dinniman, M. S., Zagorodnov, V., Tyler, S. W. \& Holland, D. M. Intrusion of warm surface water beneath the McMurdo Ice Shelf, Antarctica. Journal of Geophysical Research: Oceans 118, 7036-7048 (2013). URL http: / / dx . doi .org/10 . 1002 / $2013 \mathrm{JC} 008842$. 
[24] Moholdt, G., Padman, L. \& Fricker, H. A. Basal mass budget of Ross and Filchner-Ronne ice shelves, Antarctica, derived from Lagrangian analysis of ICESat altimetry. Journal of Geophysical Research: Earth Surface 119, 2361-2380 (2014).

[25] Crary, A., Robinson, E., Bennett, H. \& Boyd, W. Glaciological regime of the Ross ice shelf. Journal of Geophysical 67, 2791-2807 (1962). URL http : / /www . agu . org / pubs / crossref/1962/JZ067i007p02791.shtml.

[26] Neal, C. The dynamics of the ross ice shelf revealed by radio echo-sounding. Journal of Glaciology 24, 295-307 (1979).

[27] Bamber, J. \& Bentley, C. A comparison of satellite-altimetry and ice-thickness measurements of the ross ice shelf, antarctica. Annals of Glaciology 20, 357-364 (1994).

[28] Assmann, K., Hellmer, H. H. \& Beckmann, A. Seasonal variation in circulation and water mass distribution on the Ross Sea continental shelf. Antarctic Science 15, 3-11 (2003).

[29] Holland, D. M., Jacobs, S. S. \& Jenkins, A. Modelling the ocean circulation beneath the Ross Ice Shelf. Antarctic Science 15, 13-23 (2003). URL http: / / www • journals . cambridge.org/abstract_s0954102003001019.

[30] Dinniman, M. S., Klinck, J. M. \& Smith, W. O. Influence of sea ice cover and icebergs on circulation and water mass formation in a numerical circulation model of the Ross Sea, Antarctica. Journal of Geophysical Research 112, 1-13 (2007). URL http: //www . agu.org/pubs/crossref/2007/2006JC004036.shtml.

[31] Arzeno, I. B. et al. Ocean variability contributing to basal melt rate near the ice front of ross ice shelf, antarctica. Journal of Geophysical Research: Oceans 119, 4214-4233 (2014). 
[32] Brennan, P. V., Nicholls, K., Lok, L. B. \& Corr, H. Phase-sensitive FMCW radar system for high-precision Antarctic ice shelf profile monitoring. IET Radar, Sonar \& Navigation 8, 776-786 (2014). URL http: / / digital-library.theiet.org/content/ journals/10.1049/iet-rsn.2013.0053.

[33] Nicholls, K. W. et al. A ground-based radar for measuring vertical strain rates and timevarying basal melt rates in ice sheets and shelves. Journal of Glaciology 61, 10791087 (2015). URL http://www. ingentaconnect.com/content/igsoc/ jog/2015/00000061/00000230/art00005.

[34] Horgan, H. J., Walker, R. T., Anandakrishnan, S. \& Alley, R. B. Surface elevation changes at the front of the Ross Ice Shelf: Implications for basal melting. Journal of Geophysical Research 116, 1-12 (2011). URL http: / / www . agu •org/pubs/crossref / 2011/2010JC006192.shtml.

[35] Griggs, J. \& Bamber, J. Antarctic ice-shelf thickness from satellite radar altimetry. Journal of Glaciology 57, 485-498 (2011).

[36] JPL MUR MEaSUREs Project. 2010. GHRSST Level 4 MUR Global Foundation Sea Surface Temperature Analysis. Ver. 2. PO.DAAC, CA, USA. Dataset accessed [2018-0708] at http://dx.doi.org/10.5067/GHGMR-4FJ01.

[37] Kohut, J. Calibrated hydrographic data from the Ross Sea acquired with a CTD during the Nathaniel B. Palmer expedition NBP1101 (2011). Accessed on 27 Aug. 2018 (2015). URL http://www.marine-geo.org/tools/search/Files.php? data_set_uid=17595.

[38] Gade, H. G. Melting of ice in sea water: A primitive model with application to the Antarctic ice shelf and icebergs. Journal of Physical Oceanography 9, 189-198 (1979). 
[39] Gilmour, A. E. Ross Ice Shelf Sea Temperatures. Science 203, 438-439 (1979). URL http://dx.doi.org/10.1126/science.203.4379.438.

[40] Årthun, M., Holland, P. R., Nicholls, K. W. \& Feltham, D. L. Eddy-driven exchange between the open ocean and a sub-ice shelf cavity. Journal of Physical Oceanography 43, 2372-2387 (2013).

[41] Jendersie, S., Williams, M. J. M., Langhorne, P. J. \& Robertson, R. The density-driven winter intensification of the ross sea circulation. Journal of Geophysical Research: Oceans 0 (2018). URL https://agupubs.onlinelibrary.wiley.com/doi/abs / $10.1029 / 2018 \mathrm{JC} 013965$.

[42] Meier, W. et al. NOAA/NSIDC Climate Data Record of Passive Microwave Sea Ice Concentration, Version 3 (2017). Accessed 7 March 2019.

[43] Ohshima, K. I., Nihashi, S. \& Iwamoto, K. Global view of sea-ice production in polynyas and its linkage to dense/bottom water formation. Geoscience Letters 3, 1-14 (2016). URL http://dx.doi.org/10.1186/s40562-016-0045-4.

[44] Smethie, W. M., Jr. \& Jacobs, S. S. Circulation and melting under the Ross Ice Shelf: estimates from evolving CFC, salinity and temperature fields in the Ross Sea. Deep Sea Research Part I: Oceanographic Research Papers 52, 959 - 978 (2005). URL http : / / WWW.sciencedirect.com/science/article/pii/s0967063705000038.

[45] Renfrew, I. A., King, J. C. \& Markus, T. Coastal polynyas in the southern Weddell Sea: Variability of the surface energy budget. Journal of Geophysical Research: Oceans $\mathbf{1 0 7}$ (2002).

[46] Jacobs, S. \& Comiso, J. Sea ice and oceanic processes on the Ross Sea continental shelf. Journal of Geophysical Research 94, 18195-18211 (1989). URL http: / / scholar. 
google.com/scholar?hl=en\&btnG=Search\&q=intitle: Sea+Ice+and+ Oceanic+Processeston+the+Ross+Sea+Continental+Shelf\#0.

[47] Bromwich, D. H., Carrasco, J. F., Liu, Z. \& Tzeng, R.-Y. Hemispheric atmospheric variations and oceanographic impacts associated with katabatic surges across the Ross Ice Shelf, Antarctica. Journal of Geophysical Research: Atmospheres 98, 1304513062 (1993). URL https://agupubs.onlinelibrary.wiley.com/doi/ $\mathrm{abs} / 10.1029 / 93 \mathrm{JD} 00562$.

[48] Comiso, J. C., Kwok, R., Martin, S. \& Gordon, A. L. Variability and trends in sea ice extent and ice production in the Ross Sea. Journal of Geophysical Research 116, 1-19 (2011). URL http: / / www . agu . org/pubs/crossref/2011/ 2010 JC006391.shtml.

[49] Smith, W. O., Dinniman, M. S., Hofmann, E. E. \& Klinck, J. M. The effects of changing winds and temperatures on the oceanography of the Ross Sea in the 21st century. Geophysical Research Letters 41, 1624-1631 (2014).

[50] Dinniman, M. S., Klinck, J. M., Hofmann, E. E. \& Smith, W. O. Effects of projected changes in wind, atmospheric temperature, and freshwater inflow on the ross sea. Journal of Climate 31, 1619-1635 (2018). URL https://doi.org/10.1175/ JCLI-D-17-0351.1. https://doi.org/10.1175/JCLI-D-17-0351.1.

[51] Jansen, D., Luckman, A., Kulessa, B., Holland, P. R. \& King, E. C. Marine ice formation in a suture zone on the Larsen C Ice Shelf and its influence on ice shelf dynamics. Journal of Geophysical Research: Earth Surface 118, 1628-1640 (2013).

[52] Doake, C., Corr, H., Rott, H., Skvarca, P. \& Young, N. Breakup and conditions for stability of the northern Larsen Ice Shelf, Antarctica. Nature 391, 778 (1998). 
[53] Fürst, J. J. et al. The safety band of antarctic ice shelves. Nature Climate Change 6, 479 (2016).

[54] Stewart, C. L. Ice-ocean interactions beneath the north-western Ross Ice Shelf, Antarctica. Ph.D. thesis, University of Cambridge (2018).

[55] Fujita, S., Matsuoka, T., Ishida, T., Matsuoka, K. \& Mae, S. A summary of the complex dielectric permittivity of ice in the megahertz range and its applications for radar sounding of polar ice sheets. Physics of Ice Core Records 185-212 (2000).

[56] Reeh, N. On the calving of ice from floating glaciers and ice shelves. Journal of Glaciology 7, 215-232 (1968). URL http://www. ingentaconnect.com/content/ igsoc/jog/1968/00000007/00000050/art00009.

[57] Jenkins, A., Corr, H. F., Nicholls, K. W., Stewart, C. L. \& Doake, C. S. Interactions between ice and ocean observed with phase-sensitive radar near an Antarctic ice-shelf grounding line. Journal of Glaciology 52, 325-346 (2006).

[58] Thomson, R. E. \& Emery, W. J. Data analysis methods in physical oceanography (Newnes, 2014), 3 edn.

[59] Hengl, T., Heuvelink, G. B. \& Rossiter, D. G. About regression-kriging: from equations to case studies. Computers \& Geosciences 33, 1301-1315 (2007).

[60] Hansen, T. M. mGstat: A geostatistical Matlab toolbox. Online web resource (2004). URL http: //mgstat. sourceforge. net.

[61] Peng, G., Meier, W., Scott, D. \& Savoie, M. A long-term and reproducible passive microwave sea ice concentration data record for climate studies and monitoring. Earth System Science Data 5, 311-318 (2013). 
[62] Holland, D. M. \& Jenkins, A. Modeling thermodynamic ice-ocean interactions at the base of an ice shelf. Journal of Physical Oceanography 29, 1787-1800 (1999).

[63] Boyer, T. P. et al. World Ocean Database 2013. World Ocean Database; https://www.nodc.noaa.gov/. Accessed 2018-03-06 (2013).

[64] Scambos, T., Raup, B. \& Bohlander, J. Images of antarctic ice shelves, version 1. west ross ice shelf. accessed 2016. (2001). URL http://dx.doi.org/10.7265/ N5NC5Z4N.

[65] Jacobs, S. S., Fairbanks, R. G. \& Horibe, Y. Origin and Evolution of Water Masses Near the Antarctic continental Margin: Evidence from $\mathrm{H}_{2}^{18} \mathrm{O} / \mathrm{H}_{2}^{16} \mathrm{O}$ Ratios in Seawater, 5985 (American Geophysical Union, 1985). URL http://dx.doi.org/10.1029/ AR0 4 3p0059.

Corresponding author: Craig Stewart, craig.stewart@niwa.co.nz

\section{Acknowledgements}

The authors acknowledge Tom Arnold, Brett Grant and Rick Benson for assistance with the radar survey fieldwork, and Antarctica New Zealand, the Andrill programme and Woods Hole Oceanographic Institute, for field support, hot water drilling at the mooring site, and assistance with the mooring deplyment, respectively. We acknowledge Josh Kohut for the use of CTD data gathered by during the R.V. Palmer Ross Sea Expedition 2011 funded by NSF grant ANT0839039, and thank Craig Stevens for comments that improved the manuscript.

\section{Funding}

CLS was supported by the Rutherford Foundation (NZ) and Antarctica New Zealand through the Scott Centenary Scholarship.

\section{Author contributions}

CLS and MW designed and deployed the sub-ice shelf mooring. CLS designed the radar survey and CLS and PC undertook the radar fieldwork. CLS analysed the radar data with advice from KN. All authors contributed to the manuscript. 


\section{Competing interests}

The authors declare no competing interests.

\section{Data and materials availability}

SST data are available from: http://dx.doi.org/10.5067/GHGMR-4F J01. Mooring data are available at https://figshare.com/s/1c92fe8eb227b878e344. ApRES radar data are available at https: / / figshare.com/s/1255b7d76ed69e015c3a.

\section{Code availability}

Computer code used to process the radar observations is available from the corresponding author on request. 


\section{Figure captions}

\section{Figure 1}

Basal melt rates of the north-western Ross Ice Shelf. (a) Annual-mean basal melt rate observations (coloured dots) and interpolated melt rate field (background colour) with mooring location (red star) and labeled Transects TA-TC. Grey boxes indicate sites within transects. Also shown are ice thickness contours in $\mathrm{m}$ (grey) and the shear zone (dashed) that separates the Ross and McMurdo ice shelves (RIS and MIS, respectively). Background is Modis image from 10 Nov 2015 [64]. Panels (b) and (c) show annual-mean (b) and short-term summer (c) melt rates for frontal Transects TA-TC. Also shown in (b) is the mean melt rate from the Upward Looking Sounder (ULS) (red star).

\section{Figure 2}

Oceanographic conditions and melt rate variability. (a) Depth-averaged flow at the mooring site for winter (May-November; blue) and late summer (February-March; green) for calendar years 2011-2014. Also shown are the mooring site (star), R.V. Palmer CTD cast (triangle), and the region within $100 \mathrm{~km}$ of the mooring used to average SST and sea ice concentration (light blue shading). (b) TS observations from the offshore CTD cast (triangles) and from the highest subice shelf TS sensor, located $\sim 8 \mathrm{~m}$ below the ice base (stars). Also shown are the in-situ freezing point at the ice-base (blue line), representative water properties of High Salinity Shelf Water (HSSW), modified Circumpolar Deep Water (mCDW) and Antarctic Surface Water (AASW) [65], and water masses possibly derived from the offshore surface layer through interaction with the ice shelf (grey shading). Arrows indicate TS evolution associated with solar heating and ice melt. (c) Mean SST (light blue) and sea ice concentration (grey, right scale) within $100 \mathrm{~km}$ of the mooring (see Methods), and temperature measured $\sim 13 \mathrm{~m}$ below the ice base (dark blue). Also shown is SST from the offshore CTD cast (red triangle). (d) ULS basal melt rates (black) and low-pass filtered sub-ice shelf water temperature (blue, right scale).

\section{Figure 3}

SST and sea-ice concentration around Antarctica. (a) Long-term mean January SST [36] with $15 \%$ sea ice concentration [42] contour (red) (see Methods). (b) Close up of the Ross Sea additionally showing the January mean $0{ }^{\circ} \mathrm{C} \mathrm{SST}$ isotherm (white) and the $15 \%$ sea ice concentration contours for November (blue) and December (green). (c) Modis image during strong southly airfow on 10 Nov 2015 [64]. Grey boxes in (a) and (b) indicate the regions shown in (b) and (c), respectively. The red star indicates the mooring location. 


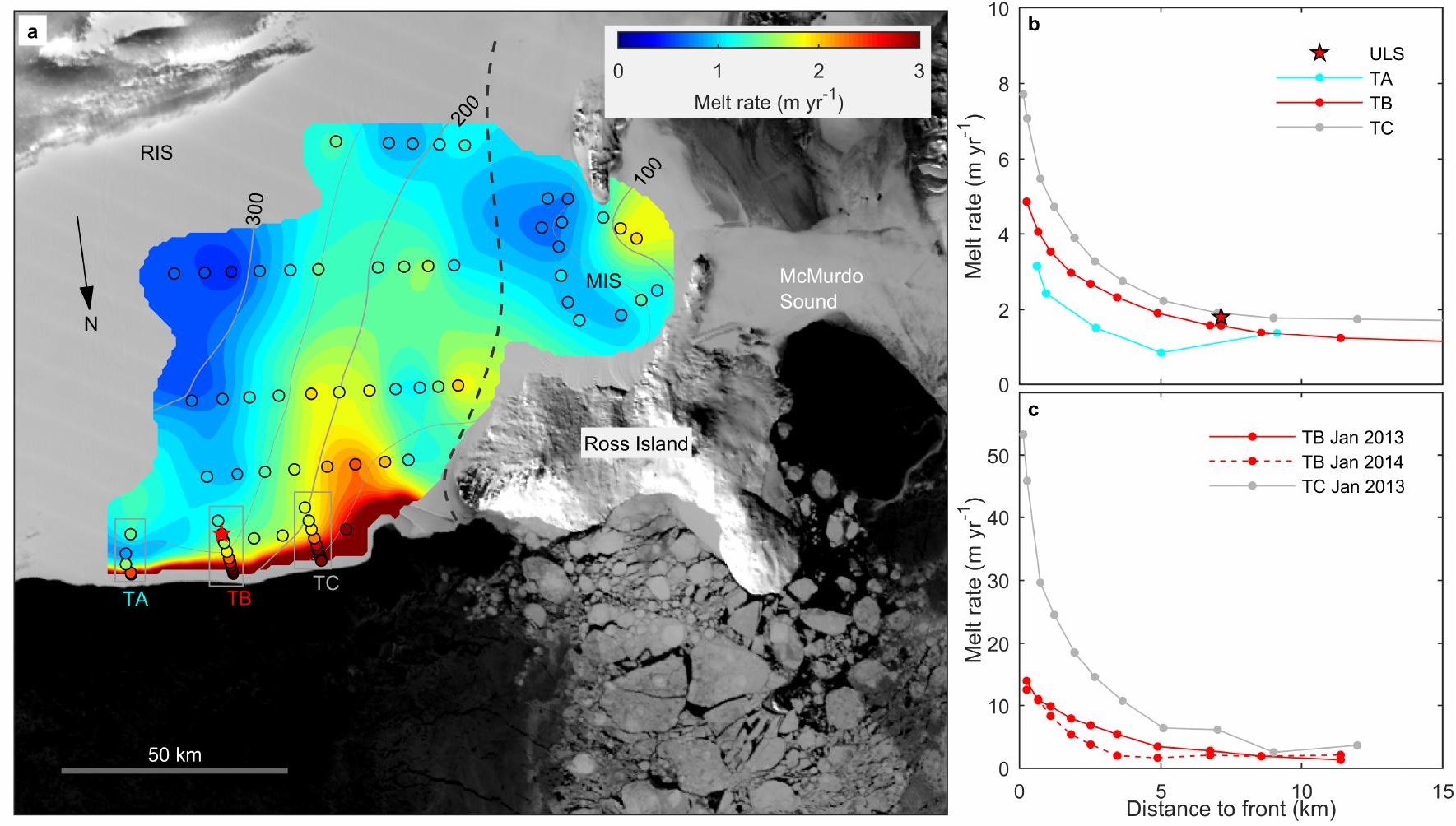




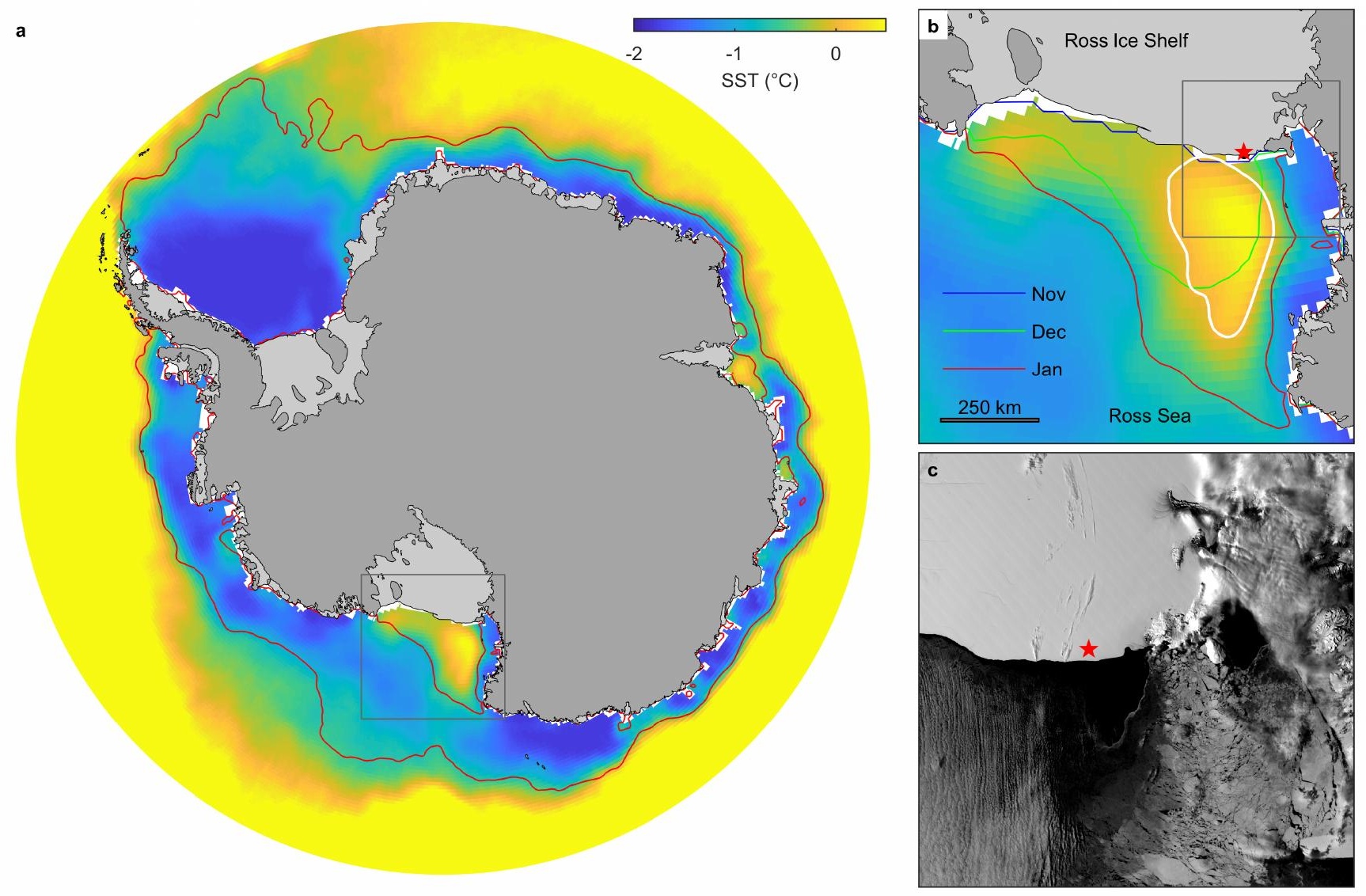

